\title{
Diagnostic double strike in the emergency room - two cases of complete pancreatic ruptures due to bicycle handlebar injuries on two consecutive days
}

\author{
A. M. Luu*, K. Meurer, T. Herzog, W. Uhl and C. Braumann
}

\begin{abstract}
Background: Pancreatic injuries are rare in cases of blunt abdominal trauma and therefore easily misdiagnosed at time of hospital admission. They are associated with a significantly elevated morbidity and lethality. Bicycle handlebar injuries are the most common cause of pancreatic trauma in children and adolescents.

Case presentation: We report two cases of a 23-year-old Caucasian woman and a 15-year-old Caucasian boy who presented to our clinic with a similar history of a bicycle accident on 2 consecutive days. Both suffered from a fall from a bicycle with bicycle handlebar injury 4 and 6 days prior to admission in our clinic. Emergency distal pancreatectomies were performed in both cases.

Conclusions: Pancreatic injuries must be highly suspected in bicycle handlebar injuries, even if amylase/lipase levels or ultrasound findings seem unremarkable. The best initial strategies are early computed tomography and a quick referral to a level 1 trauma center. Distal pancreatectomy is the treatment of choice in cases of complete rupture of the pancreatic body.
\end{abstract}

Keywords: Pancreatic rupture, Bike fall, Bicycle handlebar injury, Pancreatic fracture, Blunt abdominal trauma

\section{Background}

Pancreatic injuries are present in $0.6 \%$ of abdominal traumas in children [1]. They occur rarely because the pancreas is located in the retroperitoneum where it is relatively protected by the surrounding tissues [2]. Bicycle injuries are the most common cause of pancreatic injuries in children [3].

We report the cases of two patients who presented to our clinic 2 days in a row with a similar history of a bicycle accident and complete pancreatic rupture. These cases are presented to emphasize the importance of an early complete diagnostic workup to evaluate the severity of a blunt abdominal trauma. They were unusual due to the similar history of a misdiagnosed and underestimated life-threatening trauma as well as a referral to our clinic 2 days in a row.

\footnotetext{
* Correspondence: a.luu@klinikum-bochum.de Department of General and Visceral Surgery, St. Josef-Hospital, Ruhr -

University Bochum, Gudrunstr. 56, 44791 Bochum, Germany
}

\section{Case presentation}

\section{Case 1}

A 23-year-old Caucasian woman suffered from blunt abdominal trauma due to a fall from a bicycle onto the bicycle handlebar. She was a university student and had an unremarkable medical history. Social history was significant for occasional tobacco smoking and alcohol consumption. She was treated in a Dutch hospital for 6 days prior to transfer to our clinic. Magnetic resonance imaging (MRI) revealed complete rupture of the pancreatic body (Fig. 1): grade 3 pancreatic trauma (see Table 1) [4]. Unsuccessful stenting of the ruptured main pancreatic duct (MPD) was performed via endoscopic retrograde cholangiopancreatography (ERCP). Computed tomography $(\mathrm{CT})$-guided drainages were placed percutaneously in epigastric fluid collections. She became septic and was then transferred to our clinic with the following medication: intravenously administered metamizole $500 \mathrm{mg}$ (every 6 hours), subcutaneous octreotide 


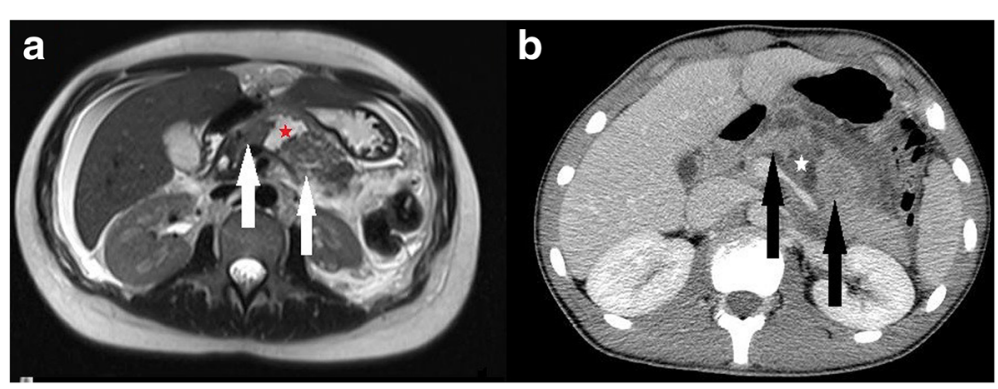

Fig. 1 T2-weighted magnetic resonance imaging (a) of patient 1 and computed tomography (b) of patient 2 depicting complete rupture of the pancreas (white and black arrows). Fluid collection between the ruptured pancreas (star)

$100 \mu \mathrm{g}$ ( 1 dose in the morning, 1 dose at midday, and 1 dose in the evening), intravenously administered pantoprazole $40 \mathrm{mg}$ ( 1 dose in the morning, 0 dose at midday, and 0 dose in the evening), and intravenously administered ceftriaxone $2 \mathrm{~g}$ ( 1 dose in the morning, 0 dose at midday, and 0 dose in the evening). On admission, she was hemodynamically unstable (blood pressure 85/65 $\mathrm{mmHg}$, heart rate 120 /minute, oxygen saturation $95 \%$, and body temperature $37.5{ }^{\circ} \mathrm{C}$ ) with a significantly increased C-reactive protein level of $212 \mathrm{mg} / \mathrm{l} \quad(<5)$ and procalcitonin level of $10.7 \mathrm{ng} / \mathrm{ml}(<0.005)$. The following laboratory values were determined as well: White blood cell count 8830/ $\mu \mathrm{l}$ (4600-9500), hemoglobin $9.8 \mathrm{~g} / \mathrm{dl}(12-16)$, thrombocytes $225,000 / \mu \mathrm{l}$ $(150,000-400,000)$, international normalized ratio (INR) 1.13 (0.8-1.1), partial thromboplastin time 30 seconds (26-40), amylase $169 \mathrm{U} / \mathrm{l}$ (13-53), lipase 183 U/1 (13-60), lactate dehydrogenase 219 U/l (135$214)$, aspartate amino transferase $21 \mathrm{U} / \mathrm{l}(10-35)$, alanine amino transferase $14 \mathrm{U} / \mathrm{l}$ (10-35), cholinesterase $2404 \mathrm{U} / \mathrm{l}(4260-11,250)$, gamma glutamyl transferase $42 \mathrm{U} / \mathrm{l}$ (6-42), alkaline phosphatase $56 \mathrm{U} / \mathrm{l}$ (35-104), bilirubin $0.4 \mathrm{mg} / \mathrm{dl}(<1.2)$, and creatinine $0.41 \mathrm{mg} / \mathrm{dl}$ (0.5-0.9). Blood cultures were positive for Pseudomonas aeruginosa. General abdominal tenderness was palpable indicating peritonitis. Her cardiorespiratory state was remarkable for tachycardia and hypotension. A neurological examination was unremarkable apart from a

Table 1 Pancreas Organ Injury Scale of the American Association for the Surgery of Trauma [4]

\begin{tabular}{|c|c|c|}
\hline Grade & Injury & Description \\
\hline 1 & $\begin{array}{l}\text { Hematoma/ } \\
\text { Laceration }\end{array}$ & $\begin{array}{l}\text { Minor contusion or superficial laceration without } \\
\text { duct injury }\end{array}$ \\
\hline 2 & $\begin{array}{l}\text { Hematoma/ } \\
\text { Laceration }\end{array}$ & $\begin{array}{l}\text { Major contusion or laceration without duct injury } \\
\text { or tissue loss }\end{array}$ \\
\hline 3 & Laceration & $\begin{array}{l}\text { Distal transection or parenchymal injury with } \\
\text { duct injury }\end{array}$ \\
\hline 4 & Laceration & $\begin{array}{l}\text { Proximal transection or parenchymal injury } \\
\text { involving ampulla }\end{array}$ \\
\hline 5 & Laceration & Massive disruption of pancreatic head \\
\hline
\end{tabular}

somnolent state. A transverse explorative laparotomy was performed immediately. On intraoperative examination, a severe peritonitis and necrotizing pancreatitis were identified as complications of a complete rupture of the pancreatic body (Fig. 2). Furthermore, the percutaneous drainage had perforated her transverse colon. A distal pancreatectomy, splenectomy, removal of the drainage, suturing of the colon perforation, and a protective ileostomy were performed. Subsequently, she underwent two further surgeries with abdominal cavity lavages. Posttraumatic complications in this case comprised severe peritonitis, necrotizing pancreatitis, critical illness polyneuropathy, and pancreatic fistula. She spent 48 days in our surgical intensive care unit and was discharged on postoperative day 68 .

A follow-up investigation 6 months after the primary surgery showed a regular postoperative state without signs of pancreatitis, fluid collections, or abscesses. Reconstruction of the ileostomy was uneventful.

\section{Case 2}

A 15-year-old Caucasian boy was transferred to our clinic exactly 1 day after case 1 . He was a middle school student and had an unremarkable medical history. His social history was unremarkable for tobacco smoking, alcohol, or drugs. Four days before, he fell from a bicycle and hit his abdomen on the bicycle handlebar just like the first patient. Initial ultrasound and laboratory tests were uneventful. However, his amylase and lipase levels were not tested. CT was performed due to progressive abdominal pain which again showed a complete rupture of the pancreatic body; once again grade 3 pancreatic trauma [4]. Laboratory values were significant for C-reactive protein $66 \mathrm{mg} / \mathrm{l}(<5)$, amylase 160 U/l (13-53), and lipase $150 \mathrm{U} / \mathrm{l}$ (13-60). The following laboratory values were determined as well: White blood cell count 9650/ $\mu \mathrm{l}$ (4600-9500), hemoglobin $12.4 \mathrm{~g} / \mathrm{dl}(14-18)$, thrombocytes $176,000 / \mu \mathrm{l} \quad(150,000-400,000), \quad$ INR 1.16 (0.8-1.1), partial thromboplastin time 37 seconds (26-40), lactate dehydrogenase $223 \mathrm{U} / \mathrm{l}(<271)$, aspartate amino transferase $16 \mathrm{U} / \mathrm{l}(<46)$, alanine amino transferase $15 \mathrm{U} / \mathrm{l}$ $(<45)$, cholinesterase $5131 \mathrm{U} / \mathrm{l}(5320-12,920)$, gamma glutamyl transferase $17 \mathrm{U} / \mathrm{l}(<29)$, alkaline phosphatase 116 


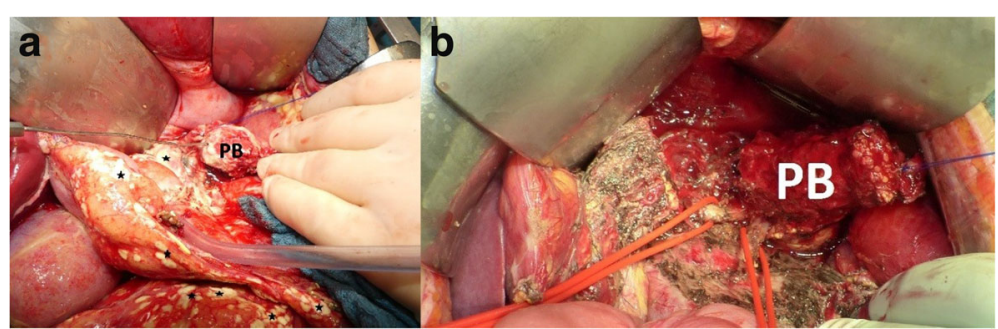

Fig. 2 Intraoperative view of complete rupture of the pancreas of patients 1 and 2. a A testing probe is inserted in the main pancreatic duct of patient 1 indicating the ruptured pancreatic body. Multiple calcifications indicate locally advanced peritonitis and necrotizing pancreatitis (stars). Right loop (b): splenic vein. Central loop (b): inferior mesenteric vein. PB pancreatic body

$\mathrm{U} / \mathrm{l}(<381)$, bilirubin $0.9 \mathrm{mg} / \mathrm{dl}(<1.2)$, and creatinine 0.56 $(0.8-1.4)$. He was then transferred to our hospital with the following medication: acetaminophen $500 \mathrm{mg}$ (1 dose in the morning, 1 dose at midday, and 1 dose in the evening) and pantoprazole $40 \mathrm{mg}$ ( 1 dose in the morning, 0 dose at midday, and 0 dose in the evening). The following vital parameters were taken on admission: blood pressure 100/ $80 \mathrm{mmHg}$, heart rate $98 /$ minute, oxygen saturation $100 \%$, and body temperature $37.9{ }^{\circ} \mathrm{C}$. A physical examination revealed a general tenderness of his abdomen indicating peritonitis. Neurological and cardiorespiratory examinations were unremarkable. An explorative laparotomy with subsequent distal pancreatectomy and splenectomy was performed. Lower grade signs of peritonitis were present intraoperatively compared to case 1 (Fig. 2). Postoperatively, he developed a pancreatic fistula. He was discharged on postoperative day 29.

A follow-up investigation 6 months after the primary surgery revealed a regular postoperative state without signs for infections, fluid collections, or abscesses.

Both patients were vaccinated against Streptococcus pneumoniae, Haemophilus influenza, and Neisseria meningitidis 6 weeks after discharge to prevent overwhelming postsplenectomy infection syndrome.

\section{Discussion}

We experienced in 2 consecutive days two rare cases of complete pancreatic rupture after bicycle handlebar injuries with significant diagnostic delay. Both patients suffered from trauma a couple of days before admission to our clinic and where treated in other hospitals first. Stenting of the MPD via ERCP was unsuccessful in patient 1 due to complete transection of her pancreas. It is of note that pancreatic injuries involving ruptures of the MPD must undergo surgical treatment [5]. In patient 2 amylase levels were not tested during admission in another hospital. Initial abdominal ultrasound was unremarkable. A CT scan was performed afterwards due to progressive abdominal pain which showed the complete transection of his pancreas. Diagnostic delay does easily occur in cases of blunt abdominal trauma, due to underestimation of the traumatic extent. Symptom-free and silent intervals can simulate an assumed recovery $[6$, 7]. Both our patients underwent emergency distal pancreatectomy and required a prolonged stay in our intensive care unit due to sepsis and peritonitis. The first patient suffered from a more severe peritonitis and critical illness polyneuropathy. Our cases confirm that delayed surgical treatment of pancreatic ruptures is associated with an increased morbidity [8].

Pancreatic injuries including complete rupture of the MPD due to blunt abdominal trauma are rare. Signs and symptoms can be minimal impeding early and correct diagnosis. Typical mechanisms of the accident are related to falls from bicycles onto the bicycle handlebars [3] or motor vehicle accidents with sudden deceleration by seatbelt straps [2]. While ultrasound of the abdomen is usually performed first, $\mathrm{CT}$, magnetic resonance cholangiopancreatography (MRCP), and ERCP are thought to be the most valuable diagnostic techniques to identify a complicated pancreatic trauma with injury of the MPD [9]. Laboratory values are significant for elevated serum amylase in $90 \%$ of cases [3]. However, in children the rise in amylase levels can be delayed for more than 12 hours after the trauma [10,11]. Non-operative strategies apply in up to $76 \%$ of cases and are common in lower grade injuries $[1,9,11]$. Higher grade injuries involving rupture of the MPD are present in 10-24\% of cases. They are usually treated surgically [1, 3, 9]. Emergency surgery is required in cases of peritonitis, large amounts of free intraabdominal fluid, evidence of MPD rupture, and complete transection of the pancreas [5]. Morbidity rate can exceed $60 \%$ while the in-hospital mortality rate is $5 \%[1,12]$. Common complications comprise pancreatitis, peritonitis, abscess formations, pseudocysts, and splenic artery aneurysms [11, 12].

Regular follow-up investigations are required 3, 9, and 15 months after surgery and include physical examination, ultrasound, and CT or MRI.

Our cases show the importance of a timely diagnosed pancreatic trauma. Diagnostic delay increases the morbidity and can have fatal consequences. Single curative 
treatment in complete ruptures of the pancreatic body is a distal pancreatectomy. Factors aggravating the morbidity include young age, severity of the injury, amylase levels, and duration of shock $[2,13]$.

\section{Conclusions}

Surgeons should be aware of pancreatic trauma especially in blunt abdominal accidents involving bicycle handlebar injuries even in cases of normal serum amylase levels or initially unremarkable ultrasound findings. A complete diagnostic workup requires repeat physical examination, sequential amylase/lipase tests, sonography, early CT of the abdomen or MRI, as well as a quick referral to a level 1 trauma center. While lower grade pancreatic injuries can respond to conservative management, complete pancreatic ruptures must be treated surgically.

\section{Acknowledgements}

Not applicable.

\section{Funding}

We acknowledge support by the DFG Open Access Publication Funds of the Ruhr-Universität Bochum. The Ruhr University Bochum did not participate in the design and writing of the manuscript.

\section{Availability of data and materials}

The authors did not use any database, software, or tools for the writing of this manuscript.

\section{Authors' contributions}

$A L, C B$, and $W U$ made substantial contributions to acquisition of data, and conception and design of the manuscript. They were involved in drafting the manuscript and revised it critically. KM and TH revised the manuscript critically and approved the final version. All authors read and approved the final manuscript.

\section{Ethics approval and consent to participate}

Not applicable.

\section{Consent for publication}

Written informed consent was obtained from the patient and the patient's legal guardian(s) for publication of this case report and any accompanying images. A copy of the written consents is available for review by the Editor-in-Chief of this journal.

\section{Competing interests}

The authors declare that they have no competing interests.

\section{Publisher's Note}

Springer Nature remains neutral with regard to jurisdictional claims in published maps and institutional affiliations.

Received: 20 November 2017 Accepted: 26 January 2018

Published online: 26 March 2018

\section{References}

1. Englum BR, Gulack BC, Rice HE, Scarborough JE, Adibe OO. Management of blunt pancreatic trauma in children: Review of the National Trauma Data Bank. J Pediatr Surg. 2016;51(9):1526-31.

2. Sutherland I, Ledder O, Crameri J, Nydegger A, Catto-Smith A, Cain T, Oliver M. Pancreatic trauma in children. Pediatr Surg Int. 2010;26(12):1201-6.

3. de Blaauw I, Winkelhorst JT, Rieu PN, van der Staak FH, Wijnen MH, Severijnen $R S$, van Vugt $A B$, Wijnen RM. Pancreatic injury in children: good outcome of nonoperative treatment. J Pediatr Surg. 2008;43(9):1640-3.
4. Moore EE, Cogbill TH, Malangoni MA, Jurkovich GJ, Champion HR, Gennarelli TA, McAninch JW, Pachter HL, Shackford SR, Trafton PG. Organ injury scaling, II: Pancreas, duodenum, small bowel, colon, and rectum. J Trauma. 1990;30(11):1427-9.

5. Houben CH, Ade-Ajayi N, Patel S, Kane P, Karani J, Devlin J, Harrison P, Davenport M. Traumatic pancreatic duct injury in children: minimally invasive approach to management. J Pediatr Surg. 2007;42(4):629-35.

6. Belyaev O, Tcholakov O, Uhl W. A traumatic pancreatic transection despite a child safety seat. Acta Chir Belg. 2017;117(3):196-9.

7. Healey AJ, Dimarakis I, Pai M, Jiao LR. Delayed presentation of isolated complete pancreatic transection as a result of sport-related blunt trauma to the abdomen. Case Rep Gastroenterol. 2008;2(1):22-6.

8. Viti M, Papis D, Ferraris V, Fiori F, D'Urbano C. Isolated and complete traumatic rupture of the pancreas: A case report and a review of the literature. Int I Surg Case Rep. 2012;3(12):590-3.

9. Cuenca AG, Islam S. Pediatric pancreatic trauma: trending toward nonoperative management? Am Surg. 2012;78(11):1204-10

10. Tolia V, Patel AS, Amundson GM. Pancreatic fracture secondary to child abuse: the role of computed tomography in its diagnosis. Clin Pediatr (Phila). 1990;29(11):667-8.

11. Klin B, Abu-Kishk I, Jeroukhimov I, Efrati Y, Kozer E, Broide E, Brachman $Y$, Copel L, Scapa E, Eshel G, Lotan G. Blunt pancreatic trauma in children. Surg Today. 2011;41(7):946-54.

12. labal CW, St Peter SD, Tsao K, Cullinane DC, Gourlay DM, Ponsky TA, Wulkan ML, Adibe OO, Pancreatic Trauma in Children Study G. Operative vs nonoperative management for blunt pancreatic transection in children: multi-institutional outcomes. J Am Coll Surg. 2014;218(2):157-62.

13. Kshirsagar AY, Vekariya MA, Pednekar AS, Mahna A, Gupta V, Patankar R, Shaikh A. Isolated pancreatic tail injury: A rare presentation. Ann Med Surg (Lond). 2015;4(3):230-2.
Submit your next manuscript to BioMed Central and we will help you at every step:

- We accept pre-submission inquiries

- Our selector tool helps you to find the most relevant journal

- We provide round the clock customer support

- Convenient online submission

- Thorough peer review

- Inclusion in PubMed and all major indexing services

- Maximum visibility for your research

Submit your manuscript at www.biomedcentral.com/submit
C Biomed Central 